\title{
28 Research Suare \\ Case Report of a Patient with Hemophagocytic Lymphohistiocytosis in Small Cell Lung Cancer
}

Wenyan Xu

First Hospital of Tsinghua University

Zhenxing Guo ( $\nabla$ gzx2962@outlook.com )

First Hospital of Tsinghua University https://orcid.org/0000-0002-8381-7547

\section{Case Report}

Keywords: hemophagocytic lymphohistiocytosis, fever, bone marrow, small cell lung cancer, case report

Posted Date: June 17th, 2020

DOl: https://doi.org/10.21203/rs.3.rs-34416/v1

License: (9) This work is licensed under a Creative Commons Attribution 4.0 International License. Read Full License 


\section{Abstract}

Background Hemophagocytic lymphohistiocytosis $(\mathrm{HLH})$ is a rare and almost universally fatal disease in adults. Due to lack of recognition, under-diagnosis or delayed diagnosis, malignancy related HLH has a poor outcome in adults.

Case Presentation A 60-year-old-female patient was admitted to our hospital with a three day history of weakness and anorexia. Physical examination revealed severe pallor without lymphadenopathy or hepatosplenomegaly. Initial blood test showed hemoglobin level of $26 \mathrm{~g} / \mathrm{L}$ and platelet count of $76 \times 10^{9} / \mathrm{L}$. Later the patient experienced sustained fever with a maximum temperature of $40^{\circ} \mathrm{C}$ for one week without any obvious infective symptoms. Biochemical examination revealed high serum ferritin and low natural killer cell viability. The bone marrow morphology showed hemophagocytosis and infiltration with metastatic small cell lung cancer (SCLC). The patient was diagnosed as hemophagocytic lymphohistiocytosis associated with SCLC and underwent chemotherapy. However, the patient progressed rapidly and died within 2 weeks.

Conclusion We reported the first HLH case with SCLC. It is critical to have an early identification of HLH in SCLC patients.

\section{Introduction}

Hemophagocytic lymphohistiocytosis $(\mathrm{HLH})$ is a syndrome of severe immune activation and proinflammatory cytokine hypersecretion, result in tissues and organs damage [1].HLH may be triggered by several factors such as drugs, autoimmune diseases and infections as well as cancers in adults. Timely diagnosis may be challenging because of the rarity of $\mathrm{HLH}$. Among them, malignancy-related HLH (M$\mathrm{HLH}$ ) is frequently miss-diagnosed with a poor outcome. The median overall survival is typically less than 2 months [2].

In this article we report a rare case of a 60-year-old female who was admitted to the department of Hematology/Oncology in The First Hospital of Tsinghua University (Beijing, China) with severe anemia, thrombocytopenia and fever for one week. Subsequently, the patient was diagnosed as small cell lung cancer (SCLC) related HLH.

\section{Case Report}

A 60-year-old female was admitted to the department of Hematology/Oncology, The First Hospital of Tsinghua University (Beijing, China) on 5 Nov, 2018 with a history of weakness and anorexia for three days. Her medical history included hypertension, hyperlipidemia and ischemic heart disease for five years, type 2 diabetes mellitus for one year. There was no obvious family history. Physical examination revealed severe pallor without lymphadenopathy or hepatosplenomegaly. Blood test showed white blood cell count $4 \times 10^{9} / \mathrm{L} \otimes$ hemoglobin $26 \mathrm{~g} / \mathrm{L} \unrhd$ platelets $76 \times 10^{9} / \mathrm{L}$ and reticulocytes $0.11 \times 10^{12} / \mathrm{L}$. The peripheral blood smear showed $4 \%$ myelocytes and metamyelocytes. Laboratory examination revealed elevated 
lactate dehydrogenase $928 \mathrm{U} / \mathrm{L}$ (normal range,120-250U/L) \total bilirubin 37.6umol/L (normal range, $\leq 20 \mathrm{umol} / \mathrm{L}$ ), indirect bilirubin $19.1 \mathrm{umol} / \mathrm{L}$ (normal range, $\leq 18 \mathrm{umol} / \mathrm{L}$ ), alanine aminotransferase 115.1U/L (normal range, 9-50U/L) \aspartate aminotransferase 70.7U/L (normal range, 15-40U/L) $\square$ alkaline phosphatase $419.9 \mathrm{U} / \mathrm{L}$ (normal range, 45-125U/L) $\varangle$-glutamyl transferase $283.8 \mathrm{U} / \mathrm{L}$ (normal range, $10-60 \mathrm{U} / \mathrm{L}$ ), creatine kinase $2172.1 \mathrm{U} / \mathrm{L}$ (normal range, 50-310U/L), triglyceride $2.52 \mathrm{mmol} / \mathrm{L}$ (normal range, $\leq 1.7 \mathrm{mmol} / \mathrm{L}$ ) . C-reactive protein $7.73 \mathrm{mg} / \mathrm{dl}$ (normal range $\otimes 0.1-5 \mathrm{mg} / \mathrm{dl}$ ), procalcitonin $0.616 \mathrm{ng} / \mathrm{mL}$ (normal range $₫ \leq 0.05 \mathrm{ng} / \mathrm{mL}$ ). Prothrombin time and activated partial thromboplastin time was within the normal range, while fibrinogen degradation product was elevated $(16.96 \mathrm{mg} / \mathrm{L}$; normal range, $\leq 5 \mathrm{mg} / \mathrm{L}$ ) , D-Dimer was $2.395 \mathrm{mg} / \mathrm{L}$ (normal range, $\leq 0.3 \mathrm{mg} / \mathrm{L}$ ) and fibrinogen (FIB) was $2.39 \mathrm{~g} / \mathrm{L}$ (normal range, $2-4 \mathrm{~g} / \mathrm{L}$ ). Human immunodeficiency virus, cytomegalovirus and Epstein-Barr virus were all negative. Also, the immunologic examinations were normal. The tumor marker test demonstrated carcinoembryonic antigen(CEA) $16.34 \mathrm{ng} / \mathrm{mL}$ (normal range, $\leq 3.4 \mathrm{ng} / \mathrm{mL}$ ), CA125 75.3U/mL(normal range, $\leq 35 \mathrm{U} / \mathrm{mL}$ ), CA199 77.69U/mL(normal range, $\leq 39 \mathrm{U} / \mathrm{mL}$ ), Cyfra $21112.39 \mathrm{ng} / \mathrm{mL}$ (normal range, $\leq 3.3 \mathrm{ng} / \mathrm{mL}$ ), NSE $311.2 \mathrm{ng} / \mathrm{mL}$ (normal range, $\leq 16.3 \mathrm{ng} / \mathrm{mL}$ ), ProGRP $\llbracket 5000 \mathrm{ng} / \mathrm{L}$ (normal range, $\leq 68.3 \mathrm{ng} / \mathrm{L}$ ), ferritin $1432 \mathrm{ng} / \mathrm{mL}$ (normal range, $30-400 \mathrm{ng} / \mathrm{mL}$ ) was elevated. Urinalysis showed haematuria and increased urobilinogen. Hemolysis related tests including Coombs' test, free hemoglobin and paroxysmal nocturnal hemoglobinuria clones were all at the normal level. Subsequent chest computed tomography (CT) scan showed right middle lobe consolidation (Figure 1). Ultrasound examination of the abdomen revealed multiple hypoechoic lesions in the liver. She was transfused with red blood cells intermittently. Despite broad-spectrum antibiotics treatment, she still experienced sustained fever with maximal temperature of $40^{\circ} \mathrm{C}$ for one week without obvious infective symptoms. Given the high suspicion of HLHखdexamethasone ( $10 \mathrm{mg}$ daily ) was started on the $5^{\text {th }}$ day. Further examination revealed decreased natural killer (NK) cell viability $11.97 \%$ (normal range, $\geq 15.11 \%$ ) and normal sCD25 1703pg/mL (normal range, $\leq 6400 \mathrm{pg} / \mathrm{mL}$ ). Subsequently, flow cytometry analysis suggested $0.04 \%$ karyota of suspected epithelial origin non-hematopoietic cells in the bone marrow aspiration. Furthermore, pathological review showed hemophagocytosis and metastatic carcinoma within the bone marrow (Figure 2). Immunohistochemical staining of bone marrow biopsy confirmed metastatic SCLC (Figure 3). The tumor cells were positive for cytokeratin (CK) 7(little +), AE1/AE3(++),

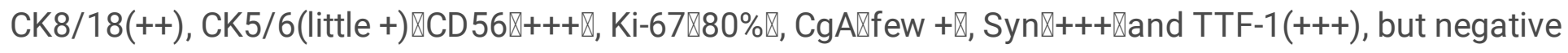
for CK20, Napsin A and P63. Up to now, the patient met five of the eight diagnostic criteria of HLH according to the HLH-2004[3]. Therefore『she was diagnosed as SCLC related HLH and quickly underwent the inductive chemotherapy regimen consist of dexamethasone and etoposide (100mg d1) according to the HLH-1994[4 ]on the $7^{\text {th }}$ day (14 Nov, 2018). However, the disease progressed rapidly. Finally, she developed a continuous febrile convulsion and died on the $12^{\text {th }}$ day (16 Nov, 2018).

\section{Discussion}

$\mathrm{HLH}$ is an excessive inflammatory reaction disease caused by uncontrolled proliferation of activated lymphocytes and histiocytes which secrete a large number of inflammatory cytokines, involving multiple tissues, organs and systems. HLH can be divided into primary HLH (pHLH) and secondary HLH (sHLH). 
pHLH mainly includes familial HLH and immunodeficiency syndrome with HLH-related gene deficiency. sHLH is associated with various underlying diseases, such as infections, tumors, rheumatologic and some metabolic diseases. Malignant tumors, especially NK/T cell lymphoma, are the main causes of sHLH. Malignancy related HLH囚M-HLHखcan occur in all age groups, and is more common in adults. A large sample study showed that M-HLH accounted for $48 \%$ of adult $\mathrm{HLH}$, of which $93.7 \%$ was caused by hematological malignancies [5]. Lymphoma is the most common type, followed by leukemia and Castleman's disease. M-HLH also occurred in a small number of patients with solid tumors, including embryonic cell tumors, thymoma, gastric cancer [6]. To our knowledge, this is the first HLH case reported with SCLC.

$\mathrm{HLH}$ is a rare and almost universally fatal disease in adults. Due to lack of recognition, under-diagnosis or delayed diagnosis, M-HLH has a poor outcome in adults. A recent study showed that fewer than $50 \%$ adult patients with $\mathrm{M}-\mathrm{HLH}$ received $\mathrm{HLH}$-directed therapy ${ }^{2}$. M-HLH patients had high mortality rate, and majority of patients died from infection and multi-organ failure within 2-4 weeks [7]. Therefore, it is very important to make a clear diagnosis and give early treatment to control the disease timely.

At present, the HLH-2004 is the commonly used international standard criteria, which requires to meet 5 of 8 criteria to make a diagnosis of sHLH [3]. Because of atypical early symptoms and rapid progress, $\mathrm{HLH}$ is easily misdiagnosed. Early identification of HLH and assessment of underlying causes are critical to formulate optimal treatment strategies. The disease progresses rapidly and has a high mortality, so it usually requires urgent treatment to suppress excessive inflammation as soon as possible.

At present, the treatment scheme of HLH-1994 is widely used in the world. Hematopoietic stem cell transplant plays a key role in improving the long-term survival rate of pHLH [8]. For M-HLH, combined chemotherapy should be given to the corresponding tumors and timely and effective supportive treatment is essential [9]. Effective infection control and comprehensive organ support may also improve the outcome of $\mathrm{M}-\mathrm{HLH}$. With the development of $\mathrm{HLH}$ research, some biological targeted agents such as alemtuzumab, interferon- $y$, tumor necrosis factor- $a$, interleukin (IL)-6, IL-1 $\beta$ and ruxolitinib have been assessed [10]. In the present study, we are fully aware of the diagnosis of HLH. The patient was hospitalized with persistent high fever and cytopenia. Further examination revealed elevated ferritin and lung tumor markers. Combined with chest CT scan, the diagnosis of M-HLH was strongly suspected. Given highly lethal disease with rapid progression of $\mathrm{HLH}$, we treated the patient with dexamethasone quickly. At the same time, we performed the examination of NK cell activity, SCD25 as well as bone marrow biopsy to confirm HLH. As soon as the patient was confirmed as HLH association with SCLC, $\mathrm{HLH}-94$ regimen was used timely. Because of the rapid progress, the patient died within two weeks. Therefore, our experience suggests SCLC related HLH has a rapid progression and high mortality. It is critical to have an early identification of HLH in SCLC patients.

\section{Conclusion}


SCLC related $\mathrm{HLH}$ is a very rare disease in adults. It progresses rapidly resulting in a high mortality. Given the extremely low incidence and limited knowledge, further studies are needed to expand the number of cases and perform a multicenter cohort study to investigate the clinical outcomes.

\section{Abbreviations}

HLH: Hemophagocytic lymphohistiocytosis; SCLC: Small cell lung cancer; CEA: Carcinoembryonic antigen; CT: Computed tomography; H\&E: Hematoxylin and eosin.

\section{Declarations}

\section{Ethics approval and consent to participate}

This study was approved by the Institutional Review Board at the First Hospital of Tsinghua University. Written informed consent was obtained from the patient for publication of this case report and the accompanying images published.

\section{Consent for publication}

Not applicable.

\section{Availability of data and materials}

Is available upon request from the corresponding author.

\section{Competing interests}

The authors declare no financial or commercial conflict of interest.

\section{Funding}

The authors did not receive any funding.

\section{Authors' contributions}

Wenyan Xu analyzed data and wrote the paper. Zhenxing Guo analyzed data and reviewed the paper.

\section{Acknowledgements}


The authors would like to thank Dr. Tamasin Evans (Western General Hospital, The University of Edinburgh, United Kingdom) for critical review of the manuscript.

\section{References}

1. Schram AM, Berliner N. How I treat hemophagocytic lymphohistiocytosis in the adult patient. Blood. 2015;125(19):2908-14.

2. Daver N, McClain K, Allen CE, Parikh SA, Otrock Z, Rojas-Hernandez C, et al. A consensus review on malignancy-associated hemophagocytic lymphohistiocytosis in adults. Cancer 2017, 123 (17), 32293240 .

3. Henter JI, Horne A, Aricó M, Egeler RM, Filipovich AH, Imashuku S, et al. HLH-2004: Diagnostic and therapeutic guidelines for hemophagocytic lymphohistiocytosis. Pediatr Blood Cancer 2007, 48 (2), 124-31.

4. Henter JI, Samuelsson-Horne A, Aricò M, Egeler RM, Elinder G, Filipovich AH, et al; Histocyte Society. Treatment of hemophagocytic lymphohistiocytosis with HLH-94 immunochemotherapy and bone marrow transplantation. Blood 2002, 100 (7), 2367-73.

5. Ramos-Casals M, Brito-Zerón P, López-Guillermo A, Khamashta MA, Bosch X. Adult haemophagocytic syndrome. The Lancet 2014, 383 (9927), 1503-1516.

6. Lehmberg K, Nichols KE, Henter JI, Girschikofsky M, Greenwood T, Jordan M, et al; Study Group on Hemophagocytic Lymphohistiocytosis Subtypes of the Histiocyte Society. Consensus recommendations for the diagnosis and management of hemophagocytic lymphohistiocytosis associated with malignancies. Haematologica 2015, 100 (8), 997-1004.

7. Tamamyan GN, Kantarjian HM, Ning J, Jain P, Sasaki K, McClain KL,et al. Malignancy-associated hemophagocytic lymphohistiocytosis in adults: Relation to hemophagocytosis, characteristics, and outcomes. Cancer 2016, 122 (18), 2857-66.

8. Cruz-Chacon A, Mathews J, Ayala E. Transplantation in rare lymphoproliferative and histiocytic disorders. Cancer Control 2014, 21 (4), 335-42.

9. Wang H, Xiong L, Tang W, Zhou Y, Li F. A systematic review of malignancy-associated hemophagocytic lymphohistiocytosis that needs more attentions. Oncotarget 2017, 8 (35), 5997759985.

10. Brisse $\mathrm{E}$, Matthys $\mathrm{P}$, Wouters $\mathrm{CH}$. Understanding the spectrum of haemophagocytic lymphohistiocytosis: update on diagnostic challenges and therapeutic options. Br J Haemato/ 2016, $174(2), 175-87$.

\section{Figures}



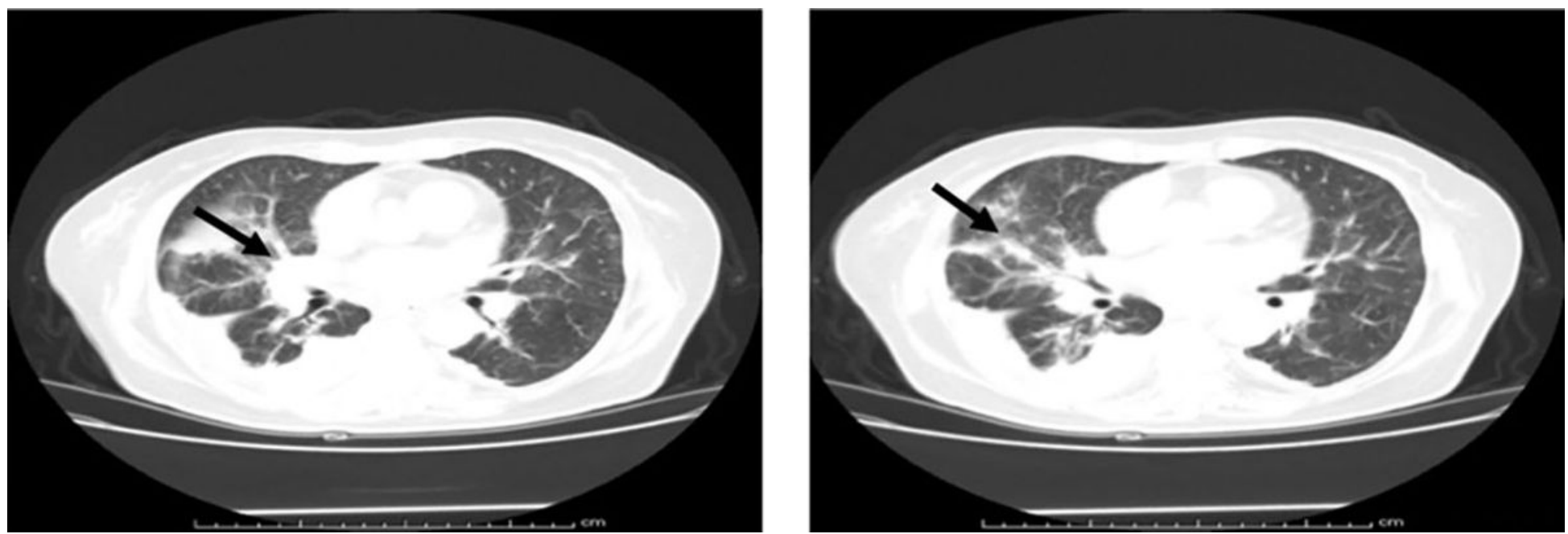

Figure 1

Chest CT revealed the right middle lobe consolidation. (arrow) Abbreviation: CT, computed tomography.
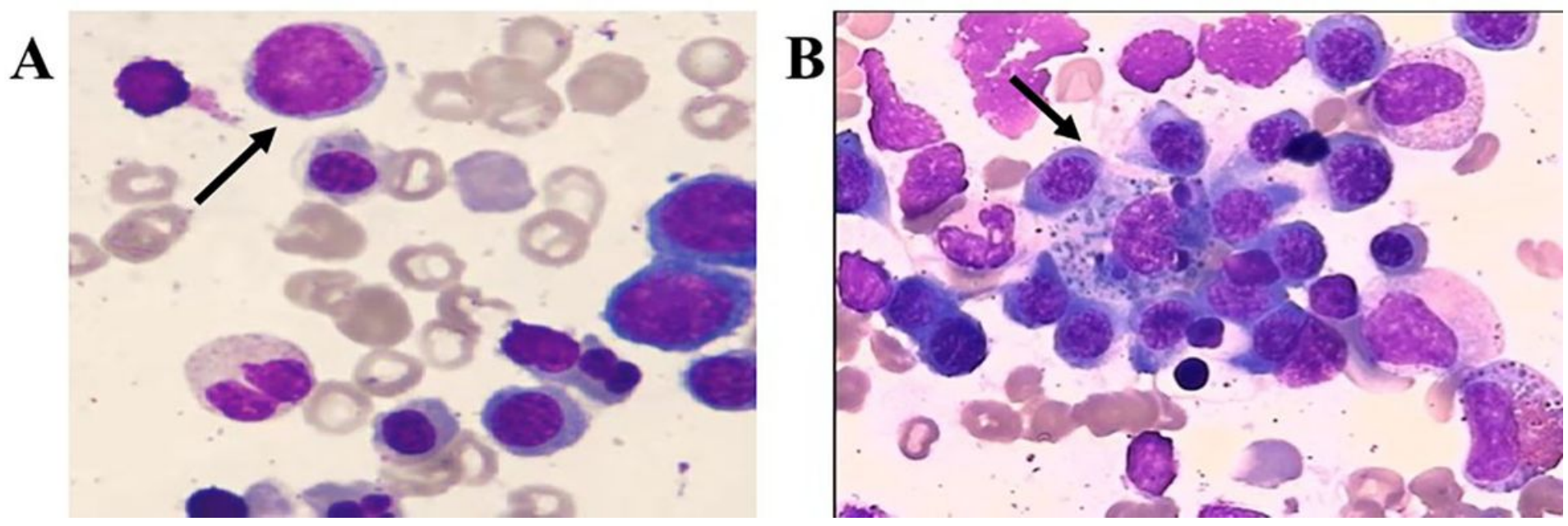

\section{Figure 2}

The morphology of bone marrow cells. Notes: The pathological result showed metastatic carcinoma of bone marrow( $A$ arrow) and hemophagocytosis (B arrow). 


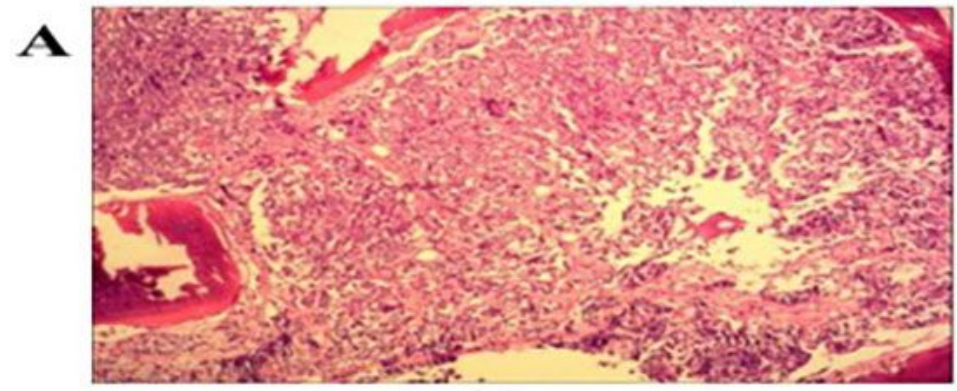

40 $\times$

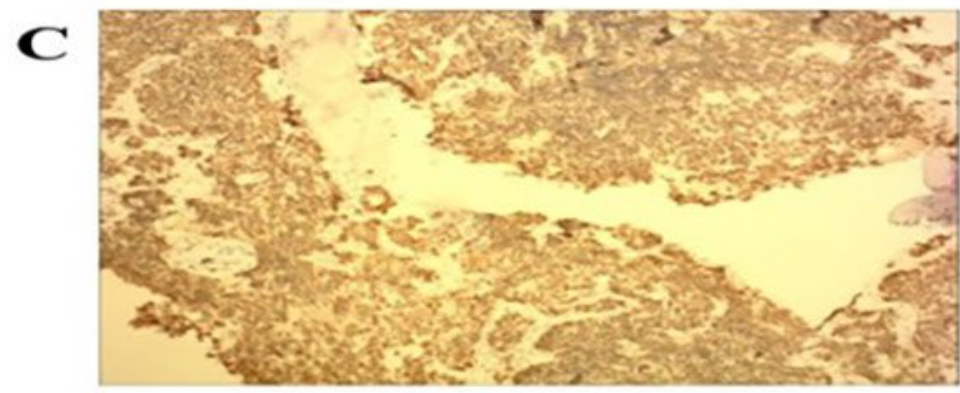

TTF-1

$\mathbf{E}$

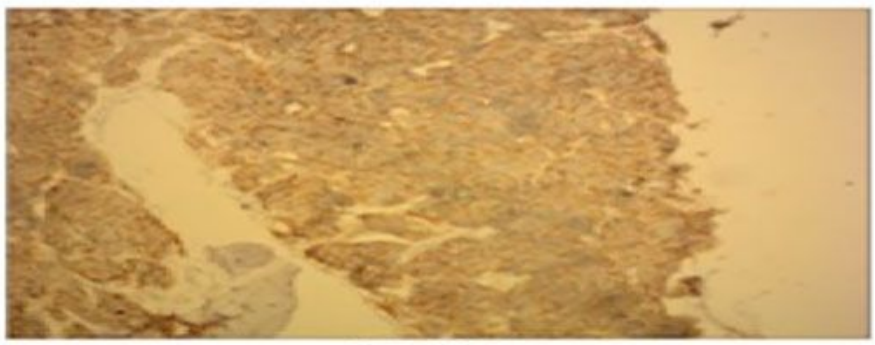

CD56

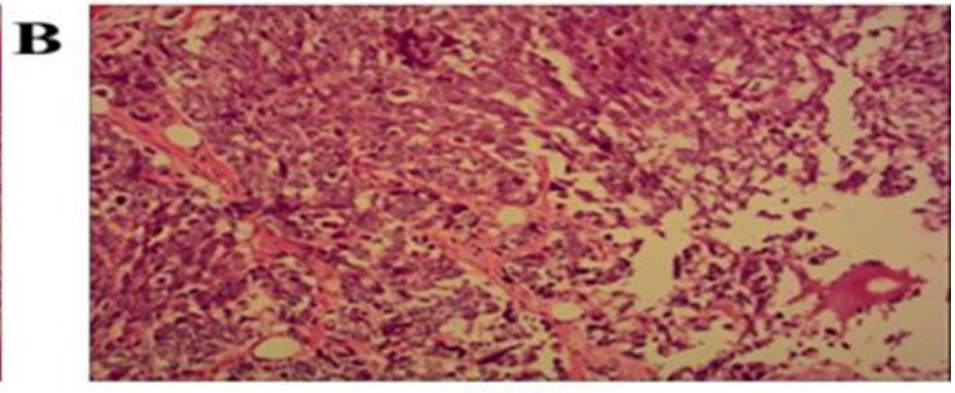

$\mathbf{2 0 0} \times$

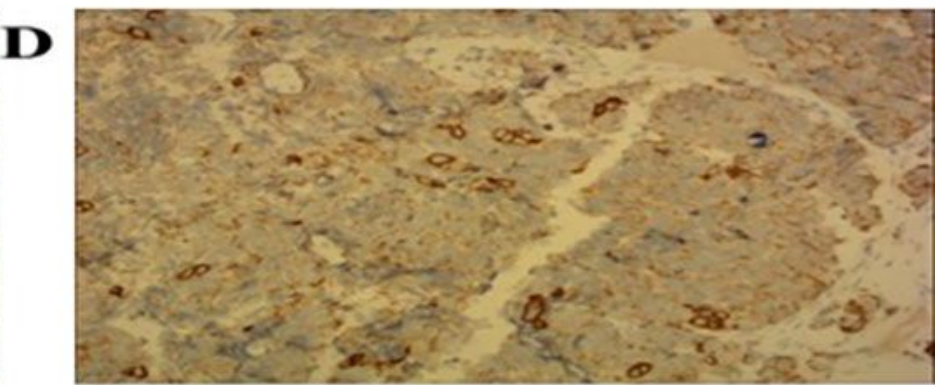

CK 7

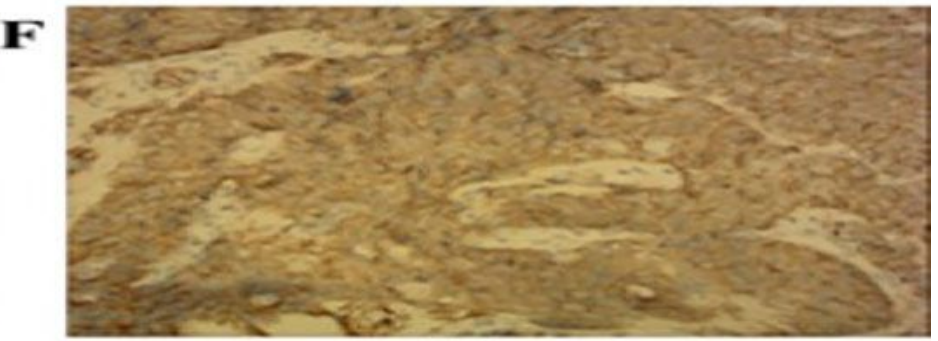

Syn

Figure 3

Histopathology of bone marrow biopsy. Notes: Histopathology of bone marrow revealed metastatic small cell lung cancer (A) (H\&E, 40x) and (B) (H\&E, 200x). Histochemical staining of tumor cells for (C) TTF1(+++) (D) CK7(little+) (E) CD56(+++) (F) Syn(+++). Abbreviation: H\&E, hematoxylin and eosin.

\section{Supplementary Files}

This is a list of supplementary files associated with this preprint. Click to download.

- CAREchecklistEnglish2013DiangPathol.pdf 